\title{
O GRANDE CIRCO MÍSTICO: UM PROJETO \\ ARTÍSTICO-PEDAGÓGICO
}

\section{THE GREAT MYSTIC CIRCUS: AN ARTISTIC-PEDAGOGICAL PROJECT}

\author{
Cristina M. Emboaba da C. J. De Camargo \\ UDESC/Florianópolis \\ criemboaba@gmail.com
}

\section{Resumo}

A realização artística e pedagógica do projeto de extensão cultural aqui descrito permite a discussão de uma formação musical fundamentada na articulação das áreas do ensino superior - Ensino, Pesquisa e Extensão - com a interação e complementariedade (Morin,2012) entre as três principais atividades musicais - poética, prática e teoria - e das disciplinas e conteúdos do currículo do curso superior de música como alternativa para uma formação musical com potência crítica, enfrentando a estrutura de fragmentação e compartimentação do conhecimento e habilidades instalada nos processos pedagógicos. Nesse recorte descrevemos e apreciamos a montagem do espetáculo $\bigcirc$ Grande Circo Místico, com as canções compostas por Chico Buarque e Edu Lobo baseadas no poema homônimo de Jorge de lima, realizado por dois programas de extensão do Centro de Artes e Departamento de Música da Universidade do Estado de Santa Catarina UDESC/FLORIANÓPOLIS com três grupos musicais e um grupo de atores, produzido pela Pró-Reitoria de Extensão e Cultura dessa universidade.

Palavras-chave: $\bigcirc$ Grande Circo Místico; Ensino Superior; Fiato al Brasile.

\section{Abstract}

The artistic and pedagogical realization of the cultural extension project described here allows the discussion of a musical formation based on the articulation of the higher education areas - teaching, 
Research and Extension - with the interaction and complementarity (Morin, 2012) between the three poetic musical activities, practice. and theory and of the disciplines and contents of the curriculum of the music college, as an alternative to a music formation with critical power, facing the structure of fragmentation and compartmentalization of knowledge and skills installed in the pedagogical processes. In this excerpt we describe and appreciate the assembly of the show The Great Mystic Circus, with the songs composed by Chico Buarque and Edu Lobo based on the homonymous poem of Jorge de Lima, performed by two extension programs of the Arts Center and Music Departament of Santa Catarina State University UDESC/FLORIANÓPOLIS with three musical groups and a group of actors, produced by the Pró-Reitoria of Extension and Culture of that university. Brasile.

Keywords: The Great Mystic Circus; Higher Education; Fiato al

Durante os anos de 2016 a 2019 as práticas musicais coletivas envolvendo os programas de extensão Engenho Musicall e Orquestra Acadêmica ${ }^{2}$ da UDESC construíram uma parceria no âmbito da extensão cultural; ambos os programas são vinculados ao Departamento de Música da Universidade do Estado de Santa Catarina, na qual sou docente, e à PROEX- UDESC para oportunizar anualmente aos discentes a possibilidade de participar e atuar em uma produção artística, desde sua concepção à performance final.

programa de extensão Engenho Musical possui três grupos que visam a prática musical coletiva: Big Band UDESC, Madrigal UDESC e Grupo de Discentes Regentes/Compositores; já o programa Orquestra Acadêmica oferece como prática musical a Orquestra de Cordas. Ambos os programas são abertos à participação da comunidade de Florianópolis e da universidade.

Nos repertórios escolhidos nesse período trabalhou-se com obras musicais de diversos gêneros e estilos, compositores e cancionistas variados. Para tanto, fez-se necessário intensificar a articulação das áreas do ensino superior - Ensino, Pesquisa e Extensão - com a interação e

I Coordenação profa. Dra. Cristina Emboaba.

2 Coordenação prof. Ms. João Eduardo Titton 
complementariedade (Morin, 2012) das três principais atividades musicais - Poética, Prática e Teoria - e das disciplinas e conteúdos do currículo do curso superior de música. $\bigcirc$ objetivo principal dessas produções musicais anuais é colaborar para uma formação musical com potência crítica ao enfrentar-se uma estrutura de fragmentação e compartimentação de conteúdos, conhecimentos e habilidades, permitindo uma concretude artística ao currículo através da produção de um espetáculo musical.

processo de montagem de um espetáculo musical exige do(a) discente uma articulação e conexão do conhecimento e habilidades adquiridos no curso de música, bem como de sua vivência musical pré -universitária, propiciando a interação desses conteúdos, até então compartimentados em suas disciplinas específicas, para a realização de uma performance real. Dessa forma, com as produções anuais o(a) discente passa a ter várias oportunidades de atuar, em diversas funções, nas montagens artísticas e musicais ao longo de seu curso, levando-o(a) a desenvolver-se a partir de sua atuação em cada produção que participe. A fim de elucidar esse processo, relatarei uma dessas experiências artístico-pedagógica vivenciadas no Departamento de Música da UDESC em 2019.

\section{O Grande Circo Místico}

A montagem aqui descrita, comentada e discutida é a obra $\bigcirc$ Grande Circo Místico, com canções de autoria de Chico Buarque e Edu Lobo, e deu-se em fases distintas envolvendo profissionais e acadêmicos de algumas universidades públicas brasileiras e escolas de música do Brasil e da Itália, como a USP (Ribeirão Preto/SP) e UDESC (Florianópolis/ SC), Escola Municipal de Música de Faenza (Itália) - Scuola Giuseppe Sarti - e Academia Livre de Música e Artes/ ALMA de Ribeirão Preto (SP).

Montado e apresentado em 2019, este espetáculo iniciou-se com as orquestrações e arranjos das canções para o Festival internacional Fiato al Brasile 2019, oitava edição, que acontece em todo mês de fevereiro na cidade de Faenza, Itália, desde 2012. Neste festival o repertório é escolhido para atender aos grupos estáveis que se formam para a semana do evento, tendo como grupos principais os corais infanto-juvenil e adulto, a orquestra de cordas, Big Band e Ensemble de flautas e clarinetes, além de artistas convidados. 
Para a edição de 2019 do Fiato al Brasile, que aconteceu de 4 a 12 de fevereiro, foram escolhidas as canções desse trabalho fonográfico de Chico Buarque e Edu Lobo como repertório principal, orquestradas e arranjadas especialmente para os grupos estáveis do festival: coros, orquestra de cordas, piano e cantores solistas. Posteriormente, esse material foi utilizado na montagem do mesmo espetáculo na UDESC em Florianópolis, ganhando uma nova versão com a participação de um grupo de sopros, a Big Band UDESC - e um grupo de atores. Além da UDESC, a edição brasileira do Festival Fiato al Brasile, que aconteceu em agosto de 2019 na cidade de Ribeirão Preto, também fez sua montagem desse mesmo espetáculo, reunindo aos grupos musicais um corpo de ballet, que é disciplina curricular na Academia ALMA, aproximandose da formação original para a qual foi escrita essa obra de Edu Lobo e Chico Buarque, como será descrito posteriormente.

Nesse artigo descreveremos as várias fases da construção desse espetáculo: os autores, o poema e o fonograma, o Festival Fiato al Brasile, a composição musical dos arranjos e orquestrações, as montagens dos diversos grupos musicais (universitários e de cursos técnicos) e a apresentação dessa obra e sua articulação/discussão com a interação entre ensino, a pesquisa e a extensão universitária.

\section{A obra e os seus autores}

A coletânea de canções $\bigcirc$ Grande Circo Místico, composta por Chico Buarque e Edu Lobo foi inspirada no poema homônimo de Jorge de Lima. Nascido em União dos Palmares (AL), o poeta-pintor-médico e jungiano Jorge de Lima (1893-1953) produziu um profícuo e singular compêndio de obras literárias e visuais, oscilando entre as palavras e as imagens, evocando o surrealismo e a religiosidade. Poemas, sonetos, pinturas, fotomontagens, colagens, são obras com conteúdos oníricos e surrealistas misturados às suas memórias e sua espiritualidade cristã, onde "poesia, vida e sonho estão intimamente ligados. Mais que isso: essas manifestações se interpenetram, eliminando os limites da lógica que separa cada uma delas" (PAULINO, 1996, p. 17).

O Grande Circo Mistico é um dos setenta e três poemas do livro A Túnica Inconsútil (1938) que tem em sua transcendência místico-religiosa uma das metáforas principais. Como toda obra de arte, este poema é em essência uma obra aberta que permite leituras diversas das

\section{3}

REV. TULHA, RIBEIRÃO PRETO, v. 6, n. I, pp. 140-166, jan.-jun. 2020 
imagens metafóricas propostas; dispõe-se à reinterpretações plásticas, sonoras e de movimento.

$\bigcirc$ poema de Jorge de Lima trata de uma dinastia de artistas circenses que serviu de insight, pesquisa e motivação poética para que dois grandes cancionistas brasileiros compusessem uma obra derivada formada por uma coletânea de canções, a princípio com um propósito bem definido:

[...] a trajetória da dinastia do Circo Knieps, uma metáfora para a busca da divindade e do absoluto, foi escolhido pelo fato de, após várias décadas de sua publicação, ter originado duas interpretações em forma de espetáculo, produzidas pelo Balé Teatro Guaíra - BTC - em 1983 e 2002. Com roteiro de Naum de Souza, coreografia de Carlos Trincheiras e músicas de Chico Buarque e Edu Lobo, - espetáculo de 1983, que recebeu o mesmo nome do poema, teve uma grande repercussão nacional e também internacional. Foi aclamado nos palcos de teatros do Brasil e de Portugal, fazendo do BTC uma reconhecida e conceituada escola de dança (QUADROS, 2011 , p. 1).

Com canções compostas originalmente para dança, o cancionista-escritor-poeta-dramaturgo Francisco Buarque de Holanda (1944), mais conhecido como Chico Buarque, e o cancionista-compositor-músico Eduardo de Cóes Lobo (1943), ou simplesmente Edu Lobo, construíram uma obra musical de intensa delicadeza com narrativas paralelas ao poema de Jorge de Lima, dialogando com outras obras literárias que tratam dessa transcendência contida na mística religiosa e da Arte. Transpuseram para o som das melodias cancionais compostas por eles a poesia, a vida e o sonho dos personagens inventados por Jorge de Lima, originando uma nova obra que marca a produção cancional da música brasileira, transcendendo os rótulos mercadológicos e fonográficos do último quartel do século XX, ganhando ao longo do tempo variadas montagens para diversas e inusitadas formações instrumentais, vocais, plásticas, teatrais e de dança. 


\section{O Poema}

Publicado em 1938 no livro de poemas A Túnica Inconsútil ( 1938), tanto o poema quanto o livro pertencem a uma fase transcendental de Jorge de Lima, com intensa preocupação mística e espiritualista. Esta corrente espiritualista (QUADROS, 2011) foi uma tendência literária de várias obras e autores na década de 1930 no Brasil, paralela ao Modernismo, e tem como um de seus representantes o poeta, escritor e pintor Jorge de Lima, que mescla "elementos espirituais e características modernistas como a narratividade e as temáticas cotidianas" (idem, p. l).

Para Quadros:

poema de uma única estrofe com 45 versos faz uso de elemento cotidianos mesclados a uma linguagem mística composta de vocábulos que dialogam com a Sagrada Escritura ("Via Sacra”,"prodígio", "devotos"), de passagens que remetem à Bíblia, como a genealogia da dinastia circense, que faz intertextualidade com o "Cênesis", e dos versos longos que lembram a narrativa bíblica, os chamados versículos claudelianos (QUADROS, 201 1, p.2).

Abaixo o poema em sua integralidade 3 :

\section{Grande Circo Místico}

Jorge de Lima

médico de câmara da imperatriz Teresa - Frederico Knieps resolveu que seu filho também fosse médico, mas o rapaz fazendo relações com a equilibrista Agnes, com ela se casou, fundando a dinastia de circo Knieps de que tanto se tem ocupado a imprensa.

Charlote, filha de Frederico, se casou com o clown, de que nasceram Marie e Oto.

E Oto se casou com Lily Braun a grande deslocadora que tinha no ventre um santo tatuado.

A filha de Lily Braun - a tatuada no ventre

$3 \bigcirc$ poema foi alinhado à esquerda para manter sua formatação original.

\section{5}

REV. TULHA, RIBEIRÃO PRETO, v. 6, n. I, pp. 140-166, jan.jun. 2020 
quis entrar para um convento,

mas Oto Frederico Knieps não atendeu,

e Margarete continuou a dinastia do circo

de que tanto se tem ocupado a imprensa.

Então, Margarete tatuou o corpo

sofrendo muito por amor de Deus,

pois gravou em sua pele rósea

a Via-Sacra do Senhor dos Passos.

E nenhum tigre a ofendeu jamais;

e o leão Nero que já havia comido dois ventríloquos,

quando ela entrava nua pela jaula adentro,

chorava como um recém-nascido.

Seu esposo - o trapezista Ludwig - nunca mais a pôde amar,

pois as gravuras sagradas afastavam

a pele dela o desejo dele

Então, o boxer Rudolf que era ateu

e era homem fera derrubou Margarete e a violou.

Quando acabou, o ateu se converteu, morreu.

Margarete pariu duas meninas que são o prodígio do Grande Circo Knieps.

Mas o maior milagre são as suas virgindades

em que os banqueiros e os homens de monóculo têm esbarrado;

são as suas levitações que a platéia pensa ser truque;

é a sua pureza em que ninguém acredita;

são as suas mágicas que os simples dizem que há o diabo;

mas as crianças crêem nelas, são seus fiéis, seus amigos, seus devotos.

Marie e Helene se apresentam nuas,

dançam no arame e deslocam de tal forma os membros

que parece que os membros não são delas.

A platéia bisa coxas, bisa seios, bisa sovacos.

Marie e Helene se repartem todas,

se distribuem pelos homens cínicos,

mas ninguém vê as almas que elas conservam puras.

E quando atiram os membros para a visão dos homens,

atiram a alma para a visão de Deus.

Com a verdadeira história do grande circo Knieps

muito pouco se tem ocupado a imprensa. 


\section{O Fonograma}

Álbum de canções lançado em 1983 pela SOM LIVRE com canções compostas em 1982 por Chico Buarque e Edu Lobo para o espetáculo homônimo encomendado e produzido pelo Balé Teatro Guaíra (Curitiba- PR), teve sua estreia em 1983, quando também foi lançado o fonograma em LP pela Som livre (1983) com concepção, roteiro, ilustrações da capa e encarte de Naum Alves de Souza e produção de Homero Ferreira. $O$ fonograma foi relançado em CD por outras gravadoras e selos como Velas, Polygram e Biscoito Fino. A direção artística é de Edu Lobo que divide os arranjos com o compositor e arranjador Chico de Moraes, este último também responsável pelas orquestrações e regência dos arranjos. Essa produção contou com um seleto grupo de músicos instrumentistas e intérpretes cantores(as) do cenário musical brasileiro. As canções e os intérpretes que compõem o fonograma ${ }^{4}$ são:

1. Oremus - intérprete Coro - 1:577.

2. Abertura do circo - Orquestra - duração 2:302.

3. Beatriz - intérprete Milton Nascimento - 5:0 13.

4. Valsa dos clowns - intérprete Jane Duboc - 3:394.

5. Opereta do casamento - intérprete Coro - 3:555.

6. A história de Lily Braun - intérprete Gal Costa - 3:516.

7. Meu namorado - intérprete Simone - 2:448.

8. Ciranda da bailarina - intérprete Coro Infantil - 2:229.

9. Sobre todas as coisas - intérprete Gilberto Gil - 5:0010.

10. O Tatuador - Instrumental - 3:2611.

11. A bela e a fera - intérprete Tim Maia - 2:5512.

12. O circo místico - intérprete Zizi Possi - 3:4113.

13. Na carreira - intérpretes Chico Buarque e Edu Lobo - 4:06

4 Informações retirados do encarte do disco LP de 1983. 


\section{Festival Internacional Fiato al Brasile}

Festival Internacional Fiato al Brasile surgiu a partir de uma fecunda relação entre o saxofonista italiano Silvio Zalambani ${ }^{5}$ (Faenza) e o compositor José Gustavo Julião de Camargo' (USP), que juntos idealizaram um intercâmbio artístico, pedagógico e cultural entre os alunos do Departamento de Música da FFLCRP-USP de Ribeirão Preto e a Scuola di Musica Giuseppe Sarti em Faenza (RA) na Itália. A ideia desse festival nasceu em 2011 , quando Silvio Zalambani ministrou um minicurso de saxofone para os alunos que tocavam instrumentos de sopro no curso de licenciatura do Departamento de Música da USP em Ribeirão Preto e se concretizou na primeira edição em fevereiro de 2012 na cidade de Faenza, Itália. Nessa edição foram para o festival cinco discentes do curso de Licenciatura do Departamento de Música, nesse período vinculado à ECANUSP campus de Ribeirão Preto e atualmente ligada à FFCLRP/USP, todos envolvidos com instrumentos de sopro e voz que tiveram aulas com professores italianos da Scuola Giuseppe Sarti durante o período de uma semana, com hospedagem e alimentação custeadas pela prefeitura de Faenza em colaboração com a Associação de Famílias italianas, cujas famílias associadas receberam os alunos em suas residências.

A partir da minha participação em 2013 no festival, quando ainda era regente dos Corais da Unesp (Campus de Franca e Jaboticabal), montou-se um coral com alunos da Scuola Giuseppe Sarti, formado por crianças e adolescentes. Além do coro, o compositor José Gustavo Julião de Camargo responsabilizou-se, juntamente com Silvio Zalambani, pela montagem de repertório e apresentação da Big Band Sarti.

Nas edições seguintes esses dois grupos formados fortaleceramse com o aumento da participação de discentes do curso de música da USP e graduandos dos cursos da Unesp que eram integrantes do projeto de extensão Coral da Unesp, dos campi de Franca e Jaboticabal (SP). Isso possibilitou a criação de um coro adulto no festival formado por esses discentes e pelos alunos dos últimos níveis da Scuola Giuseppe Sarti e pessoas da comunidade de Faenza; outra iniciativa

\footnotetext{
5 Saxofonista e professor desse instrumento do Conservatório de Trapani, Itália.

6 Compositor graduado no curso de Composição e Regência da Unicamp, regente assistente da ORQUESTRA USP FILARMÔNICA, orientador de estruturação musical, violeiro e produtor do programa de rádio Revoredo:o som da viola caipira instrumental, produzido e veiculado pela Rádio USP. É vinculado ao Departamento de Música da FFCLRP/USP.
} 
importante foi a criação do Ensemble de flautas e clarinetes por Rafael Alexandre da Silva Fortaleza (na época graduando do curso de música da USP) e pelo professor de flauta da Scuola Giuseppe Sarti Domenico Banzola (Faenza).

Firmou-se então uma parceria entre o Departamento de Música da USP e a Scuola Giuseppe Sarti, vindo a se estender para outras instituições e universidades brasileiras, como a Unesp (até 2015), a Academia Livre de Música e Artes de Ribeirão Preto - ALMA em 2015 com a participação no festival do professor dessa instituição Lucas Galon ${ }^{8}$ e a Universidade do Estado de Santa Catarina (UDESC) a partir de 2016.

A Academia9 Livre de Música e Artes de Ribeirão Preto é uma associação privada sem fins lucrativos constituída em 2015, embora já funcionasse em caráter experimental em 2014, que oferece cursos livres à comunidade dessa cidade. Em 2017 criou o núcleo de formação musical para iniciantes nas cidades vizinhas de São Joaquim da Barra e Guará (SP). Atualmente atende alunos de dez cidades circunvizinhas da região metropolitana de Ribeirão Preto, com faixa etária de 6 a 25 anos e vários níveis técnicos.

A partir de 2016 a Universidade do Estado de Santa Catarina - UDESC passa a integrar essa parceria pedagógica e artística proporcionada pelo Festival Internacional Fiato al Brasile, quando me tornei docente efetiva nas disciplinas de Prática de Regência, Prática de Coral e Prática de Conjunto no Departamento de Música dessa universidade em Florianópolis.

Nesse período consolidou-se o grupo de coordenação do Festival constituído por Silvio Zalambani (até 2017, Faenza), Donato D’Antônio $^{10}$ (Faenza), Martina Drudi (Faenza), Cristina Emboaba (UDESC), José Gustavo Julião de Camargo (USP), Lucas Galon (ALMA), Samuel Pompeo

7 Compositor, flautista, graduado pela ECA USP no curso de Música, Mestre nessa mesma instituição e doutorando no PPCMus da UFPR em composição.

8 Lucas da Silva Calon é graduado em Licenciatura pelo Departamento de Música de Ribeirão Preto da ECA-USP, atualmente pertencente à Faculdade de Filosofia, Ciências e Letras de Ribeirão Preto (FFCLRP-USP); Mestre em musicologia pelo Programa de PósGraduação da ECA-USP, e Doutor na mesma instituição.

9 Site http://www.almarp.com.br/, (acesso: 13/12/2019).

10 Violonista, professor desse instrumento e Diretor administrativo da Scuola Giuseppe Sarti de Faenza, Itália. 
(São Paulo) e Rafael Alexandre da Silva Fortaleza (UFPR), que determinam e escolhem as diretrizes pedagógicas e artísticas de cada edição do festival. Desde 2016 o Festival ganhou também edições no Brasil, sediadas no Departamento de Música da FFCLRP/USP e com produção executiva da academia ALMA, alternando assim a organização da estrutura do Fiato al Brasile. Em 2017 passa a integrar o corpo docente do festival o saxofonista brasileiro Samuel Pompeo".

Com oito versões italianas, o festival possui um braço na Finlândia desde 2016, graças a um encontro com o músico estoniano Tauno Saviauk (Conservatório Municipal de Rauma - Finlândia). Essa expansão não ocorreu por acaso: da participação de músicos italianos e brasileiros - tanto da música de concerto quanto do jazz e da música popular brasileira - às muitas obras e arranjos compostos especialmente para o festival por seus colaboradores, o festival não discrimina estilos nem filiações, mas preza pela qualidade na diversidade. Porém, o principal não pode ser esquecido: são muitos alunos brasileiros e italianos que desfrutaram dessa dinâmica arejada do festival. A singularidade do Festival Fiato al Brasile reside em sua proposta artística que tem entre seus objetivos o casamento entre Arte e Diversidade. O Fiato al Brasile buscou, ao longo de suas edições, apropriar-se das possibilidades da música contemporânea e expor uma produção atual com raízes profundas no que de se produziu na música ocidental, valorizando e legitimando também as manifestações populares brasileiras e dos saberes tradicionais.

Na edição de 2019 o grupo coordenador escolheu as canções da obra fonográfica $\bigcirc$ Grande Circo Místico para compor o repertório dos coros Infanto-juvenil e adulto, acompanhados pela orquestra de cordas do festival e piano. Para tanto, foram escritos arranjos vocais e instrumentais de treze canções do Grande Circo Mistico, com participação também de cantores solistas.

Esse mesmo repertório de arranjos e orquestrações do Grande Circo Místico foi montado em duas cidades brasileiras em 2019: na Universidade do Estado de Santa Catarina UDESC/Florianópolis em junho (com reapresentações em todo o segundo semestre de 2019) com

1 Saxofonista, professor em diversas instituições musicais da cidade de São Paulo, Mestre pelo programa de pós-graduação do IA Unesp. 
direção artística do Prof. Ms. Fernando Bresolin'2, direção musical minha e do Prof. Ms. João Eduardo Titton ${ }^{13}$ e regência dos discentes da disciplina de Prática de Regência sob minha orientação; na edição brasileira do festival Fiato al Brasile em agosto/2019 na cidade de Ribeirão Preto, este último sob a direção artística de Marisol Gallo Antonelli, José Gustavo Julião de Camargo e Lucas Galon, e direção musical e regência de Lucas Galon. Participaram dessa montagem o corpo de Ballet e Coro infanto-juvenil, ambos da academia ALMA, Coral da UNESP Franca, Orquestra Sinfônica do Festival Fiato al Brasile e solistas convidados.

\section{Orquestração e Arranjos das canções}

A coordenação do grupo de arranjadores para a elaboração do repertório para o Festival Fiato al Brasile ficou a cargo do compositor José Gustavo Julião de Camargo (USP), que convidou ex-graduandos do Departamento de Música da FFCLRP-USP, atualmente doutores e compositores, para comporem o repertório de arranjos orquestrais: Fernando Emboaba ${ }^{14}$ e Lucas Galon (ALMA). A performance desse mesmo repertório na UDESC contou com a participação do compositor Rafael Alexandre Fortaleza na elaboração da parte dos sopros, como será explicado posteriormente.

Todos os arranjos vocais dos coros ficaram sob a responsabilidade de José Gustavo, que também fez os arranjos orquestrais das canções: Abertura do Circo, Meu namorado e Sobre todas as coisas; já os arranjos orquestrais de seis canções ficaram a cargo de Fernando Emboaba: Opereta do casamento, Valsa dos clowns, A Bela e a Fera, Ciranda da Bailarina, O Circo Místico e Na Carreira; as canções A História de Lily Brown e Beatriz receberam arranjos de Lucas Galon.

Os arranjos vocais para coro infantil foram escritos a duas vozes e os do coro adulto a quatro vozes. Os arranjos orquestrais ficaram no formato tradicional de orquestra de cordas (violino I e II, viola,

12 Violinista, ator, professor substituto no Departamento de Música da Udesc na disciplina de Percepção, Mestre pelo PPCMus da Udesc e doutorando nessa mesma instituição.

13 Violinista, Mestre pelo PPCMus da UFPR e professor de violino no curso de Bacharelado na UdescUdesc.

14 Compositor, trompista, Doutor pelo PPGMus da UNICAMP em Artes, Mestre pelo PPCMus da ECA/USP e graduado no curso de Licenciatura em Música nessa mesma instituição em Ribeirão Preto. 
violoncelo e contrabaixo) e piano. Os arranjadores partiram do piano original do fonograma do Grande Circo Místico para comporem uma nova orquestração, onde alguns se aproximavam dos arranjos originais, como Abertura e Na Carreira; outras canções receberam arranjos com uma poética musical diferente à expressa no fonograma, como Sobre todas as coisas, Valsa dos Clowns e Circo Místico.

No Festival Fiato al Brasile 2019 em Faenza essa obra teve a direção musical minha e de Lucas Galon com a preparação vocal da professora Martina Drudi's (Scuola Giuseppe Sarti), que também realizou o piano; esse repertório foi performado pela orquestra de cordas do Festival, em sua maioria formada por alunos brasileiros das universidades e academia já citados anteriormente, cantado inteiramente em português pelos corais infanto-juvenis e adulto formado por alunos da Scuola Giuseppe Sarti e comunidade de Faenza e pelos cantores solistas brasileiros Yuka de Almeida Prado'6 (USP) e Tom Almeida ${ }^{17}$. A apresentação ítalo-brasileira do Crande Circo Místico foi muito bem recebida e apreciada pelo público da cidade de Faenza, que lotou o espaço de concerto do Museo Internaziolnale delle Ceramiche no dia 9 de fevereiro de 2019.

\section{Montagem do espetáculo na UDESC}

No curso de Bacharelado em instrumento e Licenciatura em Música da UDESC/FLORIANÓPOLIS sou a docente responsável pelas disciplinas de Prática Coral, Prática de Regência e Prática de Conjunto, e desenvolvo o projeto de pesquisa "O Regente e a construção da

15 Pianista e regente, professora de solfejo e coral na Scuola Giuseppe Sarti, Faenza, Itália.

16 Cantora, Mestre e Doutora pelo PPCMUS ECAUSP e professora de canto do curso de bacharelado do Departamento de Música da FFCLRP/USP.

17 Cantor e professor de História da Rede Estadual de Ensino Médio do estado de São Paulo. 
aísthesis do educando"18, que pesquisa e discute a formação do graduando em Licenciatura e Bacharelado e a sua futura coordenação e condução musical dos grupos que se formarão ao longo de sua trajetória profissional, bem como os impactos de sua atuação na construção do gosto musical e do juízo estético dos educandos sob sua responsabilidade. Este projeto é resultante da minha pesquisa de doutorado onde abordo o ensino musical numa perspectiva da Poética, da Prática e da Teoria, construindo uma formação musical alternativa aos padrões estabelecidos pela indústria da cultura $^{19}$, que monopoliza e adestra a sociedade em geral para o consumo estandardizado e customizado. Discuto também as possibilidades pedagógicas que promovam o desenvolvimento do pensamento crítico e emancipado aos padrões dessa indústria, apontando as relações da Dialética, Interação e Complementariedade como articulações que beneficiam e impulsionam a conexão

18 Projeto de pesquisa que investiga as possibilidades de formação e atuação do professor de música enquanto regente educador no processo da construção da aísthesis (sensibilidade, percepção sensorial) musical de seus educandos, processo este que é responsável pela percepção, pela formação do gosto musical e do juízo estético através da compreensão dos parâmetros musicais, dos atributos de expressão e dos princípios da poética musical que compõem as dimensões estruturais da música. A aproximação com os diferentes universos culturais e musicais pode colaborar nesse processo de construção estética ao propiciar a articulação, interpretação, compreensão e formação do pensamento crítico. Assim, a presente pesquisa tem o objetivo de investigar, a partir da Teoria Crítica (Adorno, Benjamim, Horkheimer) e dos referenciais teóricos a partir de então (Martin Heidegger, Herbert Marcuse, Luigi Pareyson, Gilles Lipovetisky, Edgar Morin, Edson Zampronha, Alexandre da Silva Costa, entre outros), as possibilidades para uma formação do professor de música com potência crítica, colaborando com sua atuação enquanto regente educador nos diferentes contextos: ensino de música na educação escolar, na educação não escolar e nas escolas especializadas de música, contribuindo para o processo de construção de uma aísthesis mais emancipada do adestramento sensorial para o consumo. As alternativas de atuação levantadas e estudadas deverão ser aplicadas na prática musical dos graduandos no exercício da função de regente educador de grupos musicais (vocais elou instrumentais)

19 Conceito trabalhado por Theodor W. Adorno e Max Horkheimer no livro Dialética do Esclarecimento (1944), mais especificamente no capítulo Indústria da Cultura. O conceito foi cunhado em aulas pelo mestre de Adorno, Sigfried Kracaver, e que se refere ao sistema ideológico/mercadológico implantado no âmbito da cultura e do entretenimento, estruturado nos países industriais liberais no início do século XX que padroniza a estesia dos indivíduos, manipulando hábitos, gostos, tradições, regras sociais, leis, interferindo na construção cultural de uma sociedade e transferindo a arte para a esfera do consumo. A produção musical da canção popular brasileira sofreu uma forte interferencia dessa estrutura industrial, pois, sendo produzida e veiculada pela indústria fonográfica para o povo, deveria obedecer aos padrões musicais estabelecidos por esse sistema mercadológico, a fim de incrementar o consumo musical nas várias camadas sociais e econômicas da sociedade brasileira do século passado. É nessa estrutura que a obra musical $\bigcirc$ Grande Circo Mistico é composta, sem, no entanto, prender-se aos padrões do consumo estabelecido pela indústria fonográfica e midiática da época.

\section{3}

REV. TULHA, RIBEIRÃO PRETO, v. 6, n. I, pp. 1 40- 166, jan.-jun. 2020 
de conhecimentos e capacidade analítica e interpretativa da pessoa em formação.

Na busca por promover esta interação entre as grandes áreas do ensino superior, entre as disciplinas da graduação em música e a articulação das principais atividades musicais - Poética, Prática e Teoria - surgiu a oportunidade de montarmos o espetáculo $\bigcirc$ Crande Circo Místico. No entanto, temos aqui um paradoxo: essa obra musical, - Grande Circo Místico, teve seu fonograma produzido e veiculado pela mesma indústria da cultura aqui mencionada como controladora de padrões estésicos ${ }^{20}$ e estéticos na sociedade. Portanto, ela pertence ao âmbito da canção de consumo. Isto não abalaria a integridade do processo quanto aos objetivos artísticos e pedagógicos acima defendidos?

Para enfrentar esse paradoxo estabelecemos uma relação dialética à própria obra que, embora em sua poética tenha uma qualidade diferenciada comparada aos padrões estabelecidos pela indústria fonográfica, ainda assim pertence à esfera do consumo de canções.

tratamento nas orquestrações como possibilidades poéticas por parte dos arranjadores, o cuidado na compreensão e interpretação das obras por parte dos discente-regentes, instrumentistas e cantores, a concepção cênica do diretor agregando à obra original discussões sociais e políticas, possibilitaram usar o texto como pretexto para trazer não só as questões da religiosidade e mística, mas também atualizar a situação do próprio artista, da arte e da complexidade social que se apresenta no Brasil de 2019.

No processo de montagem deste espetáculo procuramos construir um ambiente propício à aplicação pedagógica dos conceitos levantados na pesquisa citada, integrando primeiramente as três grandes áreas do ensino superior: Ensino, Pesquisa e Extensão, para então viabilizar as possiveis interações das disciplinas e seus conteúdos.

Na área de Extensão Cultural Universitária desenvolvo o programa Engenho Musical vinculado à Direção de Extensão, com três ações: Madrigal UDESC, Big Band UDESC e Grupo de Compositores e Regentes. Esse programa prioriza as três atividades fundamentais da música: a

20 Ligado à nossa capacidade de percepção e sensibilidade dos sentidos. 
Poética (Poíesis, composição), a Prática (Práxis, performance) e a teoria (Theoria, musicologia e pesquisa). Temos então um grupo de discentes que pesquisam, adaptam e escrevem parte do repertório "performado" pelos dois grupos Madrigal (voz) e Big Band. Tanto no Madrigal como na Big Band a responsabilidade da condução musical de cada obra alterna-se entre os discentes que se interessam e se destacam na área de Regência, sob minha orientação. Por sua vez, as pesquisas musicológicas, histórica e teórica fundamentam a escrita, a análise musical e a interpretação das obras.

A proposta de trabalho foi a junção destes dois grupos musicais acima citados com outro grupo de extensão do programa Orquestra Acadêmica da UDESC, coordenado pelo prof. Ms. João Eduardo Titton, que além de coordenar, compartilhou a estante de primeiro violino com o discente Josenir Cerqueira (spalla). A condução musical de cada canção ficou sob a responsabilidade de discentes que cursavam a disciplina Prática Regência III no primeiro semestre de 2019 (eletiva para Bacharelado e Licenciatura), que tem como conteúdo principal os fundamentos básicos para a direção orquestral. As disciplinas Prática de Regência I e II abordam a regência coral, já cursadas por esses discentes da Prática de Regência III. Assim, esses acadêmicos se responsabilizaram pela direção musical dos arranjos das canções, conduzindo a orquestra acadêmica, o Madrigal e a Big Band, sob minha orientação pedagógica e artística.

Em anos anteriores experimentamos esse formato multi e interdisciplinar com a montagem de outros dois espetáculos: Na Era do Rádio (2016 e 2017) e Cantata Ode a Zumbi, Comandante Guerreiro (2018), este último de José Gustavo Julião de Camargo, ambos com êxito de público e de receptividade na cidade de Florianópolis e interior do estado de Santa Catarina. Vale registrar que o segundo espetáculo, Cantata Ode a Zumbi, provocou polêmicas reações e discussões sobre os temas de apropriação cultural, representatividade étnica, discriminação social e racial, entre outros, que ainda necessitam ser processadas e discutidas.

Mantendo e aprimorando esse formato, os arranjos escritos para o Festival Fiato al Brasile não contemplavam ainda a sessão de instrumentos de sopros. Para incluí-los em nossa montagem foi convidado o ex-graduando da USP, o flautista Rafael Alexandre da Silva Fortaleza, atualmente doutorando em Composição pela UFPR, para escrever a

\section{5}

REV. TULHA, RIBEIRÃO PRETO, v. 6, n. I, pp. 140-166, jan.-jun. 2020 
parte de sopros para as canções Abertura, Opereta do Casamento, Valsa dos Clowns, A História de Lily Brown, A Bela e a Fera, Ciranda da Bailarina e Na Carreira. Nas canções A História de Lily Brown, A Bela e a Fera previmos a inclusão do quarteto de jazz da Big Band (guitarra, piano, baixo elétrico e bateria), além de mais duas canções vinculadas ao Grande Circo Místico: Oremus/Levitação e Anjo Azul (esta última não consta no fonograma original) e ambas com arranjos de José Gustavo Julião de Camargo para Big Band.

$\bigcirc$ pianista convidado foi 0 prof. Dr. Maurício Zamith²' (UDESC), que também orientou o discente José Corato, que gradativamente foi alternando com ele a interpretação dos arranjos ao piano. $\bigcirc$ professor Luiz Henrique Fiaminghi22, do Departamento de Música da UDESC, também colaborou para a realização desse espetáculo integrando a sessão de cordas (violino) junto aos os discentes.

A montagem contou com a direção cênica do músico, ator e prof. Ms. Fernando Bresolin (UDESC), que coordenou um grupo de atores (egressos e graduandos do curso de Licenciatura em teatro da UDESC) para comporem intervenções cênicas que desvelavam o trabalho invísivel das coxias circenses através da figura do não-artista, do hold (atendente) invisivel aos olhos do público que propicia o funcionamento da estrutura circense, bem como do cotidiano do artista de circo, desnudado do glamour do picadeiro, revelando o ser humano que se entrega à "função" interpretada, um dos temas recorrente nas canções dessa obra. Em sua concepção cênica procurou deixar aparente a precariedade de recursos em que sobrevive um grupo de artistas na tentativa de realizar obras, sejam musicais, teatrais, plásticas ou de movimento; agregou ao espetáculo um panorama alusivo à atual e precária situação da arte, da cultura e do artista em nosso país.

\footnotetext{
21 Doutor pela Universidade Federal do Rio Grande do Sul (2013), Mestre em Artes pela Universidade Estadual de Campinas (2000) e Bacharel em Música com Habilitação em instrumento (piano) pela Universidade de Sâo Paulo ECAVUSP (1995). Professor efetivo de piano nos cursos de Licenciatura e Bacharelado do Departamento de Música da Universidade do Estado de Santa Catarian UDESC.

22 Violinista, graduado em Composição e Regência pela UNICAMP, com especialização em violino barroco no Conservatório Real de Haia (Holanda) como bolsista CNPQ, especializção pela UFOP em cultura barroca, e Doutor em Práticas Interpretativas pelo PPCMUs de Artes UNICAMP, professor efetivo de Percepção Musical nos cursos de Licenciatura e Bacharelado do Departamento de Música da Universidade do Estado de Santa Catarina Udesc e integrante do Grupo Anima de música de câmara brasileira.
} 
Os discentes que dirigiram musicalmente os grupos e os respectivos cantores solistas e coro, que se alternavam a cada apresentação, foram:

1. Oremus e Levitação - Regência de Vinícius Manhães e de Pedro Rangel (alternados)

2. Abertura - Regência de Johanna Hirschler

3. Opereta do Casamento - Coro Misto/Regencia de Keyla Silva

4. Meu namorado - Contralto Johanna Hirschler/Regência de Matheus Lanzarini.

5. Valsa dos Clowns - Regência de Estevão Javela

6. Anjo Azul - Regência de Pedro Rangel

7. A História de Lily Brown - Sopranos Grasieli Facchini e Vivan Fiori/ Regência de David Toledo

8. A Bela e a Fera - Coro Masculino/Regência de Lucas Conzaga

9. Sobre todas as coisas - Baritonos David Toledo e Maitê Fontalva/ Regência de Vinícius Manhães

10. Ciranda da Bailarina - Coro Feminino/Regência de André Luiz Nunes

11. Beatriz - Tenores André Luiz Nunes e Estevão Javela/Regência de Cristian Conçalves

12. Circo Místico - Coro Misto/Regência de Jaison Oliveira

13. Na Carreira - Coro Misto/Regência de Carolina de Melo no primeiro semestre de 2019 e André Luiz Nunes no segundo semestre de 2019.

14. Abertura - Regência de Francisco Lima

Os discentes que participaram dos grupos musicais dessa montagem foram:

\section{Orquestra Acadêmica da UDESC}

Josenir Cerqueira (spalla), Carolina de Melo, Juciane Barbosa, Cindy Ferreira, Bruna Weller, Matheus Gadelha, Gabriel Niebuhr, Rafael Mota, Priscila Smaniotto, Sabrina Boldt, Francisco Lima, Paula Martins.

Coordenação prof. Ms.João Eduardo Titton 


\section{Madrigal UDESC}

Grasieli Facchini, Gabrielly Clemente, Vivian Fiori, Gabriela Passos, Ana Luiza Medeiros, Júlia Darela, Gabriela Dequech, Olga Laforet, Johanna Hischter, Lucas Conzaga, Estevão Javela, André Luiz Nunes, Matheus Lanzarini, Matheus Agostini, Eduardo Trojan, Matheus Liebsch, Antonio Montemuro, David Toledo, Lucas Fontalva, Maitê Fontalva, Felipe Lacerda, Cristian Conçalves.

Coordenação Profa. Dra. Cristina Emboaba

\section{Big Band UDESC}

Jefferson Kriese, Elisa Schmidt, Bruno Passos, Matheus de Souza, Flávio Santos, Bianca Bioni, Leonardo Almeida, Paulo Venuto, Pablo Moritz, Leon Taveri, João Salvador, Pedro Couto, Luca Maestri, João Peters, Rafael Mazini, José Corato, Rafael Nogueira, Estevão Javela, Vinícius Manhães, Pedro Rangel.

Coordenação Profa. Dra.Cristina Emboaba

Contamos com as participações dos seguintes professores do Departamento de Música da UDESC:

Prof. Dr. João Esduardo Titton - violino

Prof. Dr.Luiz Henrique Fiaminghi - violino

Prof. Dr.Maurício Zamith - piano

Profa. Dra. Cristina Emboaba - Direção musical

Prof. Ms. Fernando Bresolin - Direção artística e ator

No grupo de atores estavam Fábio Yudi Yokomizo, Joel Hallow e Katy Uabba, egressos e discentes do curso de Artes Cênicas da UDESC. Na iluminação também estavam egressos do curso de Artes Cênicas da UDESC: Iscarlat Lemos e Gabriel Velasquez. Na técnica do som tivemos 
a atuação do discente de Licenciatura em Música da UDESC Mateus Lanzarin.

A montagem desse repertório contou com a participação ativa de todos esses discentes nas funções por eles escolhidas: instrumentistas, cantores, regentes, produtores, atores, etc. A preparação dos grupos musicais foi compartilhada entre os discentes/regentes, sob minha orientação e do prof. Titton. Para a escolha dos cantores solistas foi montada uma banca examinadora formada pelos integrantes do próprio Madrigal, que analisaram e julgaram as performances vocais dos candidatos. Os discentes puderam vivenciar, além da produção musical, a produção executiva do espetáculo: elaboração de figurino, maquiagem, adereços, cenografia, montagem de palco, iluminação, transporte de equipamento, divulgação, desenvolvimento de programa, folder e cartaz.

Foram várias apresentações dessa montagem: estreia 26 de junho de 2019 no Teatro Ademir Rosa (ClC Florianópolis - SC), 14 de agosto também no Teatro Ademir Rosa, 18 de setembro no Hall do Ceart UDESC durante a Semana Integrada e Semana da Música e 15 de outubro na casa de espetáculos Arena Petry (São José E Grande Florianópolis) a convite da Associação Catarinense de Professores. Um documentário sobre essa montagem está sendo produzido pelo Núcleo de Comunicação da UDESC, com gravação integral do espetáculo e entrevistas com os participantes e que será lançado em 2020.

Assim, dois programas de extensão do Departamento de Música da UDESC (Orquestra Acadêmica e Engenho Musical - Madrigal e Big Band - formados por acadêmicos da UDESC e pessoas da comunidade da grande Florianópolis), professores voluntários do DMU e o grupo de atores (discentes e egressos do Departamento de Artes Cênicas da UDESC) reuniram-se para concretizar esse espetáculo, produzido pela Coordenação de Cultura da PROEX UDESC sob a gestão do Reitor Prof. Dr. Marcus Tomasi, Vice-Reitor Prof. Dr. Leandro Zvistes, Pró-Reitor de Extensão Prof. Dr. Fabio Napoleão com assessoria de Ivan Tonon e Ana Hofmann, numa perspectiva de interação e complementariedade, alinhados com as atuais tendências pedagógicas na universidade. 


\section{Projeto artístico como possibilidade de Interação e Articulação do Ensino, Pesquisa e Extensão.}

A montagem de um espetáculo artístico mostrou-se uma excelente oportunidade para as artes do tempo e do espaço se articularem no ensino, pesquisa e extensão universitária, construindo uma interação maior entre essas três grandes áreas do ensino superior sistêmico, bem como uma concreta interdisciplinaridade curricular entre as disciplinas responsáveis pela fundamentação teórica e prática dos cursos de artes, neste caso Música e Teatro.

Nesta montagem priorizamos a integração e interdependência dos projetos de extensão musical Orquestra Acadêmica, Madrigal e Big Band, todos da UDESC, e a interação e complementariedade entre as disciplinas da Graduação de Licenciatura e Bacharelado em Música: Prática de Regência - Prática de Coral - Prática de Conjunto - Instrumento (cordas e piano) e Música de Câmara. A associação com a pesquisa é inevitável, pois esta fundamenta e permeia as disciplinas citadas, bem como a montagem e a avaliação do processo, resultando em produções técnicas e acadêmicas, como o presente artigo, além de subsídios para discussões estéticas, poéticas, de performance e da docência. A ideia é trazer ao palco cênico o resultado, sempre em construção, de uma possibilidade pedagógica para o ensino superior e suas grandes áreas, ensino, pesquisa e extensão, mostrando e devolvendo à sociedade uma produção artística por ela subsidiada através dos impostos investidos na educação superior pública e gratuita.

As disciplinas citadas encontram-se na camada mais aparente do processo, uma vez que orbitam em torno do eixo central - a Poética -, ou seja, a obra musical escolhida para ser performada e os arranjos e orquestrações dela derivados, e ao redor da qual se desenvolveu a interação disciplinar. No entanto, numa segunda camada um pouco mais profunda estão outras disciplinas do currículo de música que preparam e fundamentam as da primeira camada, como Percepção Musical, Teoria, Harmonia, Análise. Num plano ainda mais profundo encontram-se áreas do pensamento que perpassam todas as já citadas, como Estética, Filosofia e História.

Nesta perspectiva, as relações disciplinares formam uma teia de saberes e conhecimentos poéticos, práticos e teóricos que se conectam através de conteúdos afins, vivenciados, apreendidos e discutidos pelo 
discente envolvido no processo artístico-pedagógico. $\bigcirc$ processo é coletivo, mas a aprendizagem é individual, decorrente das características, motivação e prontidão de cada discente envolvido.

Esse processo educacional e formativo possibilita ao discente, a partir de sua individualidade, desvelar suas habilidades e singularidades, pois valoriza sua função de agente ativo num processo coletivo, gerando expectativas, responsabilidade, transformação e desenvolvimento, dando sentido a conteúdos díspares e aparentemente distantes, mas que se integram e interagem na construção da performance musical e do conhecimento adquirido. A especulação de ideias, a provocação e possiveis transgressões do status quo também fazem parte do processo, resultantes da construção do pensamento crítico esperado neste processo formativo. Aos discentes participantes foi dada a liberdade de atuar dentro de suas possibilidades técnicas e motivacionais, podendo interferir, alterar e discutir o processo de montagem, e que de fato aconteceram, imprimindo características singulares a essa performance.

Neste processo artístico, inspirado e fundamentado nos conceitos e conclusões levantados em minha pesquisa de doutorado e desenvolvidos no meu projeto de pesquisa na UDESC, buscamos a interação das áreas de ensino, pesquisa e extensão, bem como "a relação entre as atividades da poética, práxis e teoria e suas respectivas disciplinas a partir de eixos comuns" (CAMARCO, 2014, p.51). A obra musical 0 Grande Circo Místico foi o eixo sincronizador na interação das áreas, disciplinas e conteúdos em torno do qual se desenvolveu o processo dessa montagem.

Foram empregados neste processo formativo os conceitos de interação e complementariedade filosoficamente construídos pelo sociólogo francês Edgar Morin 23 "buscando o diálogo inter, multi e transdisciplinar entre as diversas áreas das ciências da natureza, e destas com as humanidades" (idem, p. 52). Disciplinas compartimentadas, sem conexão entre si num currículo de música pode gerar hermetismo impossibilitando a visão e compreensão do todo. Numa situação de interação de áreas,

\footnotetext{
23 Doutor Honoris causa em diversos países, é orientador emérito no Centro Nacional da Pesquisa Científica (CNRS). Sociólogo e filósofo francês, consagra-se há mais de quinze anos "à elaboração de um 'Método' apto a aprender a complexidade do real. É autor de várias obras, e nelas se destaca a defesa do chamado pensamento complexo que, "recusando a compartimentação dos saberes e o maniqueísmo, seria capaz de reunir todo o conhecimento parcial em seu contexto e no conjunto em que ele assume um sentido" (MORIN, 2012, p.579).
} 
disciplinas e conteúdos ocorre uma relação de "complementariedade que possibilita ao educando a reorganização dos conhecimentos, que anteriormente de forma fragmentada ou compartimentada não criavam sentido" (ibidem, p. 52).

Embora este processo aproxima-se do formato da pesquisa-ação ao nomear uma ação concreta (montagem de espetáculo com programas e projetos de extensão cultural), ao delimitar um problema (aqui no caso a fragmentação e compartimentação do conhecimento e habilidades instaladas nos processos pedagógicos), e propor possiveis alternativas, como a experimentada através da montagem e performance aqui descrita do Grande Circo Místico e a fundamentação teórica de Morin (interação e complementariedade), não seguiu o processo formal da pesquisa-ação. Portanto, essa similaridade foi ocasional com a tipificação da pesquisa-ação.

Morin (2012) descreve as relações entre as disciplinas das áreas do conhecimento:

Quando nos limitamos às disciplinas compartimentadas ao vocabulário, à linguagem própria a cada disciplina -, temos a impressão de estar diante de um quebra-cabeças cujas as peças não conseguimos juntar a fim de compor uma figura. Mas a partir do momento em que temos um certo número de instrumentos conceituais que permitem reorganizar os conhecimentos -[...]-temos a possibilidade de começarmos a descobrir o semblante de um conhecimento global, mas não para chegar a uma homogeneidade no sentido holista, uma homogeneidade que sacrifique a visão das coisas particulares e concretas em nome de uma espécie de névoa generalizada. Sem dúvida, é a relação que é a passarela permanente do conhecimento das partes ao do todo, do todo à das partes [...] (MORIN, 2012, p. 491).

Assim, "a interação e a complementariedade evitariam o "acúmulo e empilhamento de conhecimentos' (ibidem, p.491), geralmente herméti$\cos$ e desconectados do todo, tão recorrentes nas diversas áreas das ciências e das humanidades" (CAMARCO, 2014, p.53). 
Neste espetáculo musical do Grande Circo Místico priorizamos esses conceitos de interação e complementariedade desenvolvidos por Morin como possibilidades de articulação das grandes áreas do ensino superior - Ensino, Pesquisa e Extensão -, das atividades musicais - Poética, Prática e Teoria - inerentes nas disciplinas e nos conteúdos do curso de Licenciatura e Bacharelado em Música, favorecendo uma construção viva, ativa, interativa e complementar do conhecimento musical. A tentativa é evitar o mero adestramento técnico gerado pelo acúmulo de conhecimento e informações, permitindo uma "religação de saberes" (MORIN, 2012) na formação musical, tornando-a provocativa, integrativa, motivando "as capacidades de análise, de julgamento, de interpretação e de compreensão" (CAMARCO, 20 | 4, p. 53).

A educação encontra-se no âmbito da cultura, de onde extrai os valores e conhecimentos por ela ensinados; uma vez que a sociedade está sob a égide de uma indústria controladora dos padrões culturais, a estrutura educacional colabora para a perpetuação da criação de consumidores dos bens culturais produzidos, desarticulando as áreas do conhecimento e dificultando, através da fragmentação e compartimentação dos conteúdos, a construção de uma visão do todo e o desenvolvimento de um pensamento crítico. 


\section{Conclusão}

Na docência encontramos possibilidades de resistência e de prováveis mudanças nos paradigmas inerentes à estrutura ideológico-mercadológica de uma indústria controladora dos padrões culturais da educação, lazer e entretenimento, saúde, arte, política; ao adotarmos procedimentos pedagógicos e artísticos que levem à construção de uma potência crítica no discente a partir da interação e complementariedade nos vários níveis da estrutura do ensino superior (das grandes áreas ao conteúdo específico), contribuímos para uma abertura curricular com alternativas que levem ao enfrentamento, adaptação e atuação a uma sociedade em rápida transformação tecnológica e de valores.

A montagem do espetáculo $O$ Grande Circo Místico (Edu Lobo e Chico Buarque) por docentes, discentes e comunidade da grande Florianópolis, com a realização dos programas de extensão da Universidade do Estado de Santa Catarina (UDESC) vislumbrou a aplicação prática dos conceitos e ideias aqui discutidos, articulando as grandes áreas do ensino superior - Ensino, Pesquisa e Extensão -, integrando as principais atividades musicais - Poética, Prática e Teoria - e buscou a interação e complementaridade dos conteúdos de várias disciplinas dos cursos de Licenciatura e Bacharelado em Música. Esse processo pedagógico possibilita as condições estruturais, poéticas, práticas e teóricas para o desenvolvimento de uma apreciação/interpretação/ performance musical, propiciando no decorrer do processo a tão almejada compreensão da obra de arte, impactando diretamente a formação do futuro docente, artista ou músico de uma sociedade em constante transformação. 


\section{Referências Bibliográficas}

ADORNO, Theodor Wiesengrund; HORKHEIMER, Max. Dialética do Esclarecimento: fragmentos filosóficos. Tradução Guido Antonio de Almeida; Rio de Janeiro: Jorge Zahar Editora, 1985, [ l a ed. 1944].

ADORNO, Theodor Wiesengrund. Educação e Emancipação. Tradução Wolfgang Leo Maar, Rio de Janeiro: Paz e Terra, 1995 [ l a ed. 1971].

CAMARCO, Cristina M. E. C. J de. O ensino musical na perspectiva da poética, da práxis e da teoria: processos de formação alternativos à indústria da cultura. 20 14, 214 p., Tese PPCMus ECA USP, São Paulo.

COSTA, Alexandre [da Silva]. "Da relação entre lógos e daímon em Heráclito: a escuta como definidora do homem". In: RICCIARDI, Rubens Russomanno; ZAMPRONHA, Edson (org). Quatro ensaios sobre música e filosofia: la ed., Ribeirão Preto, SP: Editora Corvja, 2013.

COSTA, Maria Manuela Isaías Afonso da. $\bigcirc$ valor da música na educação na perspectiva de Keith Swaanwick. 20 10, 107 f. Dissertação (Mestrado em Educação) Instituto de Educação da Universidade de Lisboa, Lisboa (Portugal), 2009/2010.

FONTERRADA, Marisa T. de O. De Tramas e Fios: um ensaio sobre música e educação. $2 a$ ed. São Paulo: Editora UNESP, Rio de Janeiro: FUNARTE, 2008.

HEIDECCER, Martin. A origem da obra de arte. Tradução Maria da Conceição Costa; Lisboa, Portugal: Edições 70, 2005 [ 1935/36, la ed. 1977].

MORIN, Edgar. A religação dos saberes - desafio do século XXI. Tradução e notas Flávia Nascimento. Rio de Janeiro: Bertrand Brasil, 2012.

PAREYSON, L. Problemas da Estética. Tradução Tradução Maria Helena Nery Garcez, Sandra Neves Abdo. I a ed. - São Paulo: Martins Fontes, 2001 [ 1984$]$. 
PAULINO, Ana Maria. Artistas Brasileiros, 1 - Jorge de Lima. São Paulo: Editora da Universidade de São Paulo, 1995.

QUADROS, Deisily. "O Grande Circo Místico: do palco à página". In: XII CONGRESSO INTERNACIONAL DA ABRALIC CENTRO, Curitiba, Centro, Centros - Ética, Estética, 201 l, s/ número de página.

REIS, Sandra Loureiro de Freitas. Elementos de uma filosofia da educação musical em Theodor Wiesengrund Adorno. Belo Horizonte: Mãos unidas edições pedagógicas Ltda, 1996.

STRAVINSKY, Igor. Poética Musical em 6 lições. Tradução Luiz Paulo Horta. - Rio de Janeiro: Jorge Zahar Editor, 1996 [ l a ed. 1942].

SWANUICK, Keith. Ensinando música musicalmente. Tradução Alda Oliveira e Cristina Tourinho, São Paulo: Modera, 2003.

\section{Sobre a autora}

Profa. Dra. Cristina Moura Emboaba da Costa Julião de Camargo é docente efetiva no Departamento de Música do Centro de Artes da Universidade do Estado de Santa Catarina - UDESC/Florianópolis desde 2015, atuando nas áreas de Regência, Coral e Prática de Conjunto. É Doutora e Mestre pelo PPCMus ECAVUSP, com bacharelado em Composição e Regência pela Universidade Estadual de Campinas - UNICAMP.

Recebido em 27/04/2020

Aprovado em 29/06/2020 